\title{
A BIOÉTICA NAS CONTINGÊNCIAS DO TEMPO PRESENTE - A CRÍTICA COMO DESTINO?
}

\author{
Flávia Regina Souza Ramos ${ }^{1}$, Rosane Gonçalves Nitschke², Laurete Medeiros Borges ${ }^{3}$
}

\footnotetext{
${ }^{1}$ Doutora em Filosofia em Enfermagem. Professor Associado do Departamento de Enfermagem e do Programa de Pósgraduação em Enfermagem (PEN) da Universidade Federal de Santa Catarina (UFSC). Pesquisadora CNPq. Santa Catarina, Brasil.E-mail: flaviar@ccs.ufsc.br

${ }^{2}$ Doutora em Filosofia em Enfermagem. Professor Associado do Departamento de Enfermagem e do PEN/UFSC. Santa Catarina, Brasil. E-mail: nitschke@mbox1.ufsc.br

${ }^{3}$ Doutoranda do PEN/UFSC. Professora do Instituto Federal de Santa Catarina. Santa Catarina, Brasil. E-mail: laurete@ifsc. edu.br
}

RESUMO: Ensaio reflexivo que busca problematizar a bioética como discurso contemporâneo. Após um inventário sobre as múltiplas possibilidades de mapear conceitos, posições e formas de contar a história da bioética, são destacados dois eixos argumentativos - a idéia da bioética em uma forte adesão/pertinência a um modo de ser e viver no século XX nas sociedades ocidentais, de viver na ambigüidade entre a ameaça e a fortuna - as dificuldades e conflitos da bioética para realizar sua tarefa crítica. Finaliza ressaltando o caráter político e cultural que cerca a emergência e o destino da bioética, além das variadas perspectivas e sujeitos envolvidos nas negociações que constituem este discurso.

DESCRITORES: Bioética. Filosofia. Saúde.

\section{BIOETHICS IN PRESENT TIME CONTINGENCIES - CRITIQUE AS A DESTINATION?}

ABSTRACT: This is a reflexive paper which seeks to discuss bioethics as contemporary discourse. After an inventory about the multiple possibilities of mapping concepts, positions, and forms of telling the bioethics story, two arguments are highlighted - the idea of bioethics in a strong bonding/pertinence to a manner of being and living in the 20th century in occidental societies, of living in the ambiguity between threat and fortune - the difficulties and conflicts of bioethics in order to carry out its critical task. This article finalizes by pointing out the political and cultural character which surrounds the emergence and destination of bioethics, beyond the various perspectives and subjects involved in the negotiations which constitute this discourse.

DESCRIPTORS: Bioethics. Philosophy. Health.

\section{LA BIOÉTICA EN LAS CONTINGENCIAS DEL PRESENTE - ¿LA CRÍTICA COMO DESTINO?}

RESUMEN: El presente ensayo tiene por objetivo problematizar la bioética como un discurso contemporáneo. Después de realizar un inventario sobre las múltiples posibilidades de mapear conceptos, posiciones y formas de contar la historia de la bioética, son destacados dos ejes argumentativos - la idea de la bioética como una fuerte adhesión/pertinencia a un modo de ser y de vivir de las sociedades occidentales en el siglo XX, de vivir en la ambigüedad, entre la amenaza y la fortuna - y, las dificultades y conflictos de la bioética para realizar su tarea crítica. El ensayo finaliza resaltando el carácter político y cultural que cerca la emergencia y el destino de la bioética, además de señalar las diversas perspectivas y sujetos involucrados en las negociaciones que constituyen este discurso. DESCRIPTORES: Bioética. Filosofía. Salud. 


\section{INVENTÁRIO INICIAL}

Atualmente, há variadas formas de inventariar o percurso da Bioética e sua bagagem acumulada. Somente a simples compilação de escritos sobre a história e classificações da Bioética já comporia um razoável conteúdo. Mas qual é o melhor ordenador destes conteúdos, o que fornece a melhor chave para articular e entender tantas idéias em torno de um mesmo termo?

Seria pelo acompanhamento das transformações e proposições conceituais, oferecidas por diferentes autores, buscando-lhe o contexto de emergência e de enunciação de cada conceito divulgado (pelo menos aqueles que contabilizaram maior influência)? Seria buscar na ordem dos acontecimentos, aqueles que marcaram e produziram consequências notáveis para o desenvolvimento da bioética? Seria pela adoção de uma idéia central a partir da qual se buscaria argumentos pertinentes, favoráveis ou não, a tomada da bioética sob tal ângulo? Por exemplo, ao tentar responder se a Bioética seria ou não uma nova disciplina, ou um paradigma. Ou seria, ainda, pela historiografia de seu âmbito mais institucional e normativo, na trilha das regras práticas que compuseram este edifício político institucional internacional?

Seja pela via dos acontecimentos reivindicatórios e impactantes, seja pela via de divulgadores e estudiosos ilustres, ou ainda pela abordagem a partir de campos teórico-práticos específicos, como o direito ou a medicina, já temos disponíveis textos que situam este inventário em uma ou outra chave interpretativa. ${ }^{1-9}$

Obviamente que tais estudos só podem ser citados a título de exemplos representativos, uma vez que muitos outros existem, se aproximando destes pelo tipo de argumento ordenador da análise, ou oferecendo outras tantas formas de discutir a bioética. O que têm em comum é o interesse em situar e circunscrever a bioética na contemporaneidade em perspectivas mais ou menos ampliadas, fora da preocupação temática estrita (questões e problemas bioéticos específicos). Já esta abordagem temática é, sem dúvida, responsável por uma vasta produção bibliográfica.

Duas obras norte americanas pioneiras foram os estudos historiográficos de Rothman, citado como primeiro historiador do movimento da bioética, e de Jonsen..$^{10}$ Em muitos outros estudos posteriores, percebe-se a influência destas duas obras na forma de entender a emergência o impacto da bioética na área biomédica. Embora a idéia de pio- neirismo não seja aqui melhor tratada, é importante constatar que, mesmo com algumas posições críticas quanto ao fato da bioética ser uma produção norte americana, este pioneirismo continua sendo retratado - não apenas porque os acontecimentos eleitos como marcantes em sua história ocorreram nos Estados Unidos, mas porque ali se considera que as reações a estes acontecimentos foram pioneiras, (enquanto fatos semelhantes aconteciam em outros lugares). ${ }^{7,9}$ Também porque ali alguns se colocaram como responsáveis por iniciativas que, se tinham intenções de abrangência local ou nacional, se propagaram velozmente.

No entanto, pode-se considerar que outro tipo de pioneirismo se dará mais tarde, exatamente em torno de propostas e teorizações que rompem com os limites do marco norte americano e de seus interesses, para ampliar o compromisso da bioética com os excluídos - seja do ponto de vista de direitos político-sociais (populações excluídas), como do ponto de vista da hegemonia de um discurso (temas excluídos da pauta bioética norte americana). Na perspectiva da agenda, pauta, temáticas ou teorizações da bioética surgem demarcadores de novos campos (ou subcampos) dentro da bioética, a partir dos quais movimentos intelectuais e políticos se evidenciam. Três destas formas de nomear são exemplares e serão aqui citadas.

Primeiramente, a proposta da Bioética Cotidiana (problemas morais e científicos que dizem respeito ao dia-a dia de milhões de pessoas) em distinção a uma Bioética de Fronteira ou de situações limites (questões dilemáticas mais precisamente definidas, envolvendo os processos de nascer, viver e morrer mediados pelo desenvolvimento tecno-científico). ${ }^{11-12}$ A proposição de uma Bioética de Situações Persistentes (problemáticas como a exclusão social, a descriminação e preconceito, a iniqüidade ou a violência) em distinção à uma Bioética de Situações Emergentes (desafios relacionados à novas tecnologias terapêuticas e reprodutivas, à engenharia genética, transplantes, entre outras).$^{13}$ Desta alternativa se desdobra o que é denominado de uma Bioética Forte ou Bioética de Intervenção, na perspectiva dos excluídos e como projeto de construção de um novo arcabouço crítico e epistemológico, numa clara ruptura com a aplicação da bioética como ferramenta neutra de leitura despolitizada dos conflitos morais. ${ }^{13} \mathrm{E}$, num outro exemplo, a diferenciação entre a microbioética da macrobioética, sendo que enquanto a primeira se situa mais no âmbito clínico e interpessoal, a macrobioética se coloca como social, desenvolvendo 
instrumentos para análises institucionais, políticas e culturais que envolvem processos sociais, especialmente a saúde pública. ${ }^{14}$

Os três exemplos indicam a intencionalidade e propositividade de formas de nomear, em contraposições a discursos que conquistaram a autoridade de legitimamente falar em nome da bioética e sobre a bioética. Mas que idéias, e que transformações podem ser captadas ao olharmos mais atentamente para estes discursos? Que relações estes fragmentos-idéias teriam com o vigor do próprio discurso? E, mais uma vez, cabe realçar que o uso de discursos, no plural, remete a consideração de que embora possamos identificar a bioética a um grande campo, domínio ou movimento, este é multifacetado, atravessado por leituras e valorizações particulares aos espaços de diversas disciplinas. Um discurso e muitos discursos, expressão da complexidade de muitas vozes, em muito dissonantes e, por alguns meios, orquestradas.

O reconhecimento desta amplitude pode ser sinalizado por estudo que diferencia características da bioética, inicialmente, pelo modo como esta pretendeu se distinguir da deontologia médica, chegando às suas abordagens interdisciplinar, secular, prospectiva, global e sistêmica, para afirmar quatro tendências quanto ao modo de conceber a bioética, como - fórum; método de análise; processo de regulação ou forma de ética. ${ }^{5}$

O que uma só obra abre de possibilidades de mapear conceitos e posições, pode ser multiplicado algumas vezes ao se percorrer um conjunto significativo delas. Seria então produtivo qualquer novo esforço de mapeamento? Ou para qual nova demanda se justificaria tal empenho ou mesmo retomada? Obviamente que uma demanda, um interesse ou uma zona cega identificada movimenta um conjunto já produzido. Aqui o movimento buscado nada mais é do que o de uma problematização, " no sentido foucaultiano, ${ }^{15}$ do que de mais notável tem a bioética, daquilo que nos faz admira-la e valorizá-la: sua capacidade de dizer por nós as coisas das quais precisamos, das nossas circunstancias, do nosso mundo; falando, em diversos tons e formas, para que não deixe ninguém de fora da sua capacidade de representar a todos.

Uma problematização que, antes de desenhar o mapa discursivo da bioética, a vê como se fosse um mapa do presente, sinalizando ameaças, perdas, posições, alvos, territórios e alianças. Pessoas, nomes, lugares, instituições e qualificações não se ausentam, já que nunca deixam de ocupar suas posições num discurso que não será apagado, mas figuram como personagens móveis, representativos de uma verdade que veiculam e ajudam a fortalecer.

A chave para a leitura deste mapa não é uma indicação exata, mas algumas perguntas, que servem apenas para recolocarmo-nos frente a bioética: - que tipo de problema a bioética se propôs a formular ou para que tipo de problema se pôs a buscar respostas? Que tipo de problemas fez pensar a bioética como resposta? - que tipo de poder entra em jogo para recorrer ao saber bioético?; - que tipo de fertilidade a bioética pode produzir para nutrir certa diversidade e descontinuidade sem perder uma coerência, uma unidade discursiva reconhecível, um parentesco, um fundo projetivo comum? Que tipo de unidade foi possível de ser produzida na diversidade do jogo estratégico da bioética? Ou que tipo de diversidade coexistiu com esta unidade, ou mesmo a produziu?

Um mapa mostra conteúdos. O mapa da bioética, do seu discurso, mereceria ser tratado como repertório interpretativo, ${ }^{16}$ como conjunto de termos, conceitos, expressões de linguagens mobilizadas ao se falar de um fenômeno peculiar; como produções culturais inscritas em diferentes tipos de texto e manifestações da memória social; como reservatório de sentidos produzidos na relação com o mundo e nos movimentos de sua compreensão.

Pela impossibilidade de responder a tão complexas perguntas, talvez delas se possa, inicialmente, tirar um jeito de reler os mesmos textos, ou um jeito de pôr em evidência algumas ambiguidades. Tal exercício de problematização da bioética como discurso contemporâneo (significativo de e para o tempo presente) é o objetivo deste ensaio. Após este inventário inicial, o mesmo será abordado por dois tópicos eleitos, a seguir.

Dizer de um sentido foucaultiano para problematização remete ao fazer "algo" entrar no jogo da verdade, tornar-se objeto do pensamento. Nas palavras de Foucault "Problematização não quer dizer representação de um objeto preexistente, nem tampouco a criação pelo discurso de um objeto que não existe. É o conjunto das práticas discursivas ou não discursivas que faz alguma coisa entrar no jogo do verdadeiro e do falso e o constitui como objeto para o pensamento (seja sob a forma da reflexão moral, do conhecimento científico, da análise política, etc.)". .5:242 $^{2}$ 
ENTRE A AMEAÇA E A FORTUNA - A PREMÊNCIA DO ACONTECIMENTO E A INCERTEZA DO AMANHÃ

"Nós temos uma grande necessidade de uma ética da terra, uma ética para a vida selvagem, uma ética de populações, uma ética do consumo, uma ética urbana, uma ética internacional, uma ética geriátrica e assim por diante... Todas elas envolvem a bioética, [...] Eu proponho o termo Bioética como forma de enfatizar os dois componentes mais importantes para se atingir uma nova sabedoria, que é tão desesperadamente necessária: conhecimento biológico e valores humanos. [...] O que nós temos que enfrentar é o fato de que a ética humana não pode estar separada de uma compreensão realista da ecologia em um sentido amplo. Valores éticos não podem estar separados de fatos biológicos [...] como indivíduos nós não podemos deixar nosso destino nas mãos de cientistas, engenheiros, tecnólogos e políticos que esqueceram ou nunca souberam estas verdades elementares" ${ }^{\prime 17: 2}$

Se antes, havia um pano de fundo cultural conhecido de todos, sendo discutido das mais diversas formas, e destrinchado em seus potenciais, agora, para o bem ou para o mal, as sociedades se defrontam com um possível que se multiplica em diferentes imagens, de acordo com cada realidade e expectativa, podendo, muitas vezes, ser traduzido como impensável, assustador, ou mesmo, fantástico. Entretanto, neste percurso pelo tempo, a capacidade de projetar, imaginar, prever, olhar para o futuro se singulariza, sendo inigualável a períodos precedentes.

A ciência da previsão e da prospecção é um a priori ou condição histórica da emergência da bioética. A capacidade de olhar para o futuro, conquistada pela ciência, foi em certa medida, o que a colocou no campo visual deste mesmo olhar. Na obviedade da relação ciência e bioética, ainda cabe destacar aqueles aspectos deste tempo da ciência que mais contribuíram para esta reviravolta do olhar. Deixando um pouco de lado as palavras de ordem deste tempo, como alta tecnologia, o que resta? $\mathrm{O}$ que nos caracteriza quando se desfoca da arma biológica, dos sofisticados equipamentos para manter a vida ou da manipulação genética, para citar apenas alguns? O que pode se insinuar nesta lente desfocada? Da arma biológica para o bioterrorismo e o pânico moral, ${ }^{18}$ da sofisticação tecnológica para manter a vida para a mudança nos modos de morrer, lenta e solitariamente. Em todos os casos, um sujeito encurralado pelo medo e ansioso por saber mais, por manipular a vida, por conquistar mais garantias contra a insegurança, por vencer a angústia.

Numa abordagem foucaultiana, admite-se a carência de instrumentos conceituais para a análise da vontade de saber ${ }_{1}^{19}$ que acaba por se utilizar de noções desgastadas e emprestadas da antropologia e psicologia (curiosidade, angustia diante do desconhecido, necessidade de domínio e apropriação), de generalidades históricas (espírito de uma época, concepção de mundo) ou, ainda, de temas filosóficos (como o horizonte de racionalidade). Ou seja, as tentativas de definir modelos teóricos para analisar este sujeito que deseja saber mais e mais são ainda insuficientes e provisórias.

O que se pode levantar é a pertinência da bioética para este sujeito, que é também a própria condição para que esta se faça necessária, daí a idéia de a priori. Deste terreno e deste sujeito muito mais do que a bioética floresceu e, muitas vezes, bem antes dela, de forma que não há como precisar encadeamentos lineares de progressão ou causação. Que fatos precisos, que características deste sujeito ocidental do século XX impulsionaram um nascimento? Questões talvez rudimentares, que desviam da idéia de uma prática discursiva, como modos de fabricação de discursos, que ganham corpo em conjuntos técnicos, instituições, esquemas de comportamento, formas pedagógicas, que possuem delimitações provisórias e podem reunir ou atravessar diferentes disciplinas ou ciências e, possuem modos de transformações específicos, produzidos fora, dentro ou ao lado delas (em outras práticas discursivas). ${ }^{17}$

O que cumpre ressaltar neste momento é a idéia da bioética com uma forte adesão e pertinência a um modo de ser e viver no século XX nas sociedades ocidentais, ou seja, de viver na ambigüidade entre a ameaça e a fortuna. Ou, seja, ameaça entendida como tudo o que coloca em risco uma existência que permita e expressão de uma genuína humanidade, enquanto a fortuna se refere a tudo que venha contribuir, potencializar e enriquecer o existir genuinamente humano. Isto pode ser discutido por meio de algumas possibilidades ou impossibilidades que funcionam como condições desta pertinência, anteriormente referi$\mathrm{da}$, ressaltando-se a reversibilidade constante que existe entre ameaça e fortuna.

Uma primeira seria a possibilidade de conhecer a ameaça, reconhecer riscos, até mesmo prever suas chances de ocorrência, sua magnitude, sua eclosão, distribuição e dispersão, suas causas e consequências; enfim, estabelecer a cadeia da pre- 
disposição ao dano, à sequela, e toda uma série de opções de intervenção sobre a ocorrência, antes e depois dela. Para tal, servindo-se de inúmeros instrumentos, da estatística à história, para com isto munir um olhar que denuncia, próximo daquele da anatomopatologia, que inaugurou a clínica, um olhar mudo como um dedo apontado: "[...] O olhar vai direto: ele escolhe, e a linha contínua que ele traça opera, em um instante, a divisão do essencial; ele vai além do que vê; as formas imediatas do sensível não o enganam; pois ele sabe atravessalas; ele é desmistificador por essência". 20:123

Semelhante ao corpo sobre a mesa de exame, à célula sob a lente do microscópio, a sociedade de risco está sob averiguação. A averiguação deve eliminar a incerteza, o obscuro e o impenetrável do objeto, para ser prova de uma verdade; mas, neste caso, esta eficiência não se conclui. Se a codificação, homogeneização e normalização do corpo, teve na clínica seu aparato de maior sucesso, não se pode colocar em igual situação as tecnologias que insinuaram tamanha tarefa no corpo social, também tomado pela ciência. Toda a potente tecnologia da ciência moderna para ler o real, produzir visibilidade e descritibilidade, não é assim tão perfeita. A impossibilidade da pureza do real é que fratura a consistência da verdade científica. Afinal, qual verdade? Entre a multiplicidade de enunciados e interpretações se expõem a verdade como produção, agora impura, desde sempre regulada para circular e fazer funcionar sua própria instituição. O conhecimento que assegurou o domínio das coisas, correlato do projeto político da modernidade, já não basta.

Assim, como a clínica precisou de um corpo e o produziu, a biopolítica precisou de populações e as produziu, a bioética precisou das ameaças e fortunas da ciência, e as produziu. Não que antes inexistisse corpo ou população, mas que estes seriam totalmente outros, depois de tomadas como objeto e efeito de saber e do poder. Talvez a bioética apenas precariamente perfaça caminho semelhante, mas não se pode negar que está a fabricar uma moral para a ciência. Um conhecimento, uma demanda, uma exigência que só teriam sentido no interior do mesmo projeto de sujeito que alimentou a ciência moderna.

Os excertos recolhidos (conceitos autorizados) são bem indicativos: crescentes demandas, ampliadas e diversificadas, que extrapolam os contextos estritos das disciplinas científicas, todas relacionando ética como necessidade em que tais necessidades, "todas elas envolvem a bioética" ${ }^{17: 2}$
A bioética sem fronteiras, a bioética que busca uma sabedoria, a bioética que toma nosso destino das mãos de outro, ou que deseja saber em nome de qual valor este outro pode exercer tal poder. Esta bioética pergunta por um saber, em nome do qual se intervem, mas pergunta também por um valor, por uma justificação moral, que dariam consistência moral à ação e legitimariam seus impactos.

Mas a bioética não é apenas uma grande e importante necessidade, ela também é urgente, na mesma medida em que a sociedade do risco será também a sociedade da urgência, do acontecimento que não pode esperar. Do mesmo modo que o olhar de longo alcance (para o futuro) se mostra como uma condição preliminar, a sobrevivência como meta coloca a bioética como imperiosa. Disto decorrem outras três possibilidades, ou condições de pertinência, ligadas todas a esta primeira e que podem ser apresentadas como: uma interessante posição das disciplinas; uma super-exposição na rede de informação e, a condição que talvez englobe todas a anteriores, ou seja, como uma atitude de crítica e de modernidade.

A maior circulação e interpenetração dos discursos das disciplinas científicas entre si e, com toda uma linguagem derivada de processos e insumos tecnológicos, empurrou as reflexividades para além de suas fronteiras e produziu hibridismos e novos problemas. Obviamente que a bioética, para além de já se apresentar nesta zona de intercâmbio e cooperação de linguagens, a evoca ainda mais, recorrendo a esta situação de abrandamento das vigilâncias de fronteiras para se colocar como exemplarmente capaz de demonstrar sua capacidade e sua exigência de ser inter ou trans disciplinar.

Só que, ao assim se movimentar, de certa forma retoma a ilusão de uma unidade ou universalidade no campo moral, impensável do ponto de vista de sua realidade litigiosa e problemática ou, de modo mais incisivo, do seu caráter aporético. Neste caso, talvez se tenha que pensar no sentido mais comum, como aquele que circula nas escolas de medicina e enfermagem, em que o predicado interdisciplinar é atribuído à bioética por uma idéia de que ela articularia a reflexão moral aos problemas da vida e das práticas de saúde, trazendo a contribuição, a fundamentação, a sabedoria filosófica ao alcance e à aplicação prática, esta sim tão humanamente conflituosa.

Inicialmente, é comum se incorrer na cisão entre moral (concebida como teoria, fundamento neutro, naturalmente clara e bem intencionada) 
e problemas vividos (concebidos como práticos, complexos e corrompidos por interesses) como campos relativamente isolados e "reuníveis" por meio desta capacidade de interpelação. Sobre um e outro campo, há saberes legítimos (a ética e as ciências da vida), de estatutos diferenciados, mas, agora, demandados por um único sujeito, o sujeito moral. A meta do homem moderno de ser sujeito moral de suas ações é corporificada no trabalhador da saúde (ou no cientista, jurista, professor) autônomo, responsável e justo. A que recorrer? Onde buscar ferramentas? Já que não deixa de ser uma tarefa a que se lança bem munido. Recorre-se a esta interessante e útil posição das disciplinas - elas agora conversam. A disciplinarização da moral e moralização da técnica seriam consequências desta cisão.

Outra condição a destacar seria a extrema exposição do temas bioéticos numa sociedade de informação, tornando-a uma bandeira obrigatória. De certa maneira, há que se pensar na bioética como uma espécie diferente de artefato cultural $^{21}$ ou como produtora de significados que são condições para o funcionamento de certas práticas sociais ou, ainda, como um tipo próprio de articulação de significados sociais produzidos em diversas práticas (políticas, científicas, acadêmicas, jurídicas). Nesta situação, não há desacordo sobre o empenho pela bioética expressando uma dimensão coletiva e interdisciplinar. Nenhum discurso que a isto se opusesse seria cabível, não apenas entre os pares, sendo também inaceitável para uma época que vive o risco, a incerteza e a quebra da confiança plena no conhecimento.

De qualquer forma, um tempo em que acontecimentos singulares como o abuso no tratamento dos sujeitos de pesquisas biomédicas, antes confinado ao escrutínio de poucos, pôde ganhar o espaço público, foi o tempo favorável para a emergência da bioética. Questões privadas das práticas científicas e assistenciais podem ser debatidas por todos; certas regras e lógicas de como as coisas funcionam estão relativamente ao alcance e passam a ser assediadas por outros discursos em movimento, fazendo surgir novas pautas e renovando estes próprios movimentos. ${ }^{22} \mathrm{Ou}$ seja, um cenário em que temas como a preservação ambiental, as iatrogenias do desenvolvimento tecnológico ou os direitos humanos estão em foco, é o cenário mais atento para receber novas denúncias ou novas conquistas, e suas decorrentes inseguranças.

Daí que outra condição perpassa tais possibilidades - uma atitude de modernidade e sua relação com uma atitude crítica como "certo modo de pensar, de dizer e também de agir, um tipo de relação com o existente, com aquilo que se sabe, com o que se faz, uma relação com a sociedade, com a cultura, com os outros". ${ }^{23: 31}$ Pode-se resumir algumas características desta crítica - o fato de existir sempre em relação a algo diverso de si, como instrumento ou passagem para um futuro ou verdade, que apela para uma utilidade rigorosa e um imperativo ou virtude geral; - sua vinculação com o amplo processo de governamentalização, próprio das sociedades ocidentais a partir do século XVI, a uma explosão da arte de governar os homens e seu deslocamento do recinto religioso para múltiplos espaços (laicização); - tem seu núcleo nas relações entre poder, verdade e sujeito, ou no jogo da política da verdade, como um movimento em que os sujeitos são capazes de reconhecer em si o "direito de interrogar a verdade em seus efeitos de poder" 23:41 - remete ao projeto de sujeito moderno, em que o empreendimento crítico põe em questão a própria razão, como responsável por excesso de poder (crítica da razão presunçosa). Daí emerge o procedimento analítico inaugurado por Kant, de questionar sobre "qual idéia falsa teve o conhecimento acerca de si mesmo? A que uso excessivo encontrou-se exposta e, consequentemente, a que forma de domínio ligou o próprio destino?". ${ }^{23: 8}$

Ao pensarmos a atitude de modernidade como condição para tão ampla aderência da bioética aos projetos de sociedade em suas versões mais contemporâneas, podemos também problematizar o conteúdo ou destino crítico desta mesma bioética. Daí caberia explorar, sob que condições e argumentos a bioética se coloca como crítica ou criticamente fundamentada; se há supostos consistentes para pensá-la nesta sua vocação crítica, auto-retratada.

\section{ENTRE CONTINGÊNCIAS E LIMITES: A CRÍTICA COMO DESTINO FORJADO E INSOLÚVEL (?)}

"Bioética é o estudo sistemático da conduta humana na área das ciências da vida e a atenção à saúde, enquanto que esta conduta é examinada a luz dos princípios e valores morais. [...] Bioética é o estudo interdisciplinar do conjunto das condições exigidas para uma administração responsável da vida humana, ou da pessoa humana, tendo em vista os progressos rápidos e complexos do saber e das tecnologias biomédicas. [...] A bioética é o estudo dos comportamentos desejáveis em matéria 
de intervenções médicas sobre a vida humana [...] A bioética é pois uma forma de ética, e essa ética, no sentido em que a entendemos aqui, consiste em elaborar juízos, em formular compromissos, diretrizes e políticas indispensáveis em uma sociedade pluralista, quando indivíduos ou grupos se enfrentam em questões referentes à medicina ou às ciências da vida" ${ }^{* * 24: 1}$

Depois de um cenário que aperfeiçoou e tornou aceitável e meritório certo olhar sobre as feridas e sucessos da sociedade científicotecnológica, também se torna aceitável que o destino da bioética se prendesse a uma tomada de posição legítima. Estas posições representam, estrategicamente, canais para dirigir, reter, suprir e abastecer, drenar em fluxos direcionados os caminhos nada naturais da ciência e da técnica. Assim, o exame ou inquérito - que conferiu uma forma jurídica-política à produção da verdade apropriada ao Estado moderno e disto obteve o respaldo para se generalizar e se impor como modelo de saber ${ }^{24}$ - terá ainda que cumprir seu papel sobre as ações e comportamentos de um outro tipo de sujeito: aquele que sempre teve a prerrogativa de conhecer e intervir, aquele habituado a ser o examinador. Mas haverá novos instrumentos de análise a serem aplicados sobre as mãos que detêm a própria tecnologia sob exame? Que instrumentos analisam instrumentos e seus exímios operadores?

As técnicas de investigação da verdade no domínio jurídico (inquérito) estenderam sua aplicação para o âmbito da ciência e da reflexão filosófica, na medida em que emergiram como derivações de um mesmo conjunto de controles sócio-políticos de uma época. ${ }^{25}$ Se pensarmos a bioética como usuária e operadora de análogos instrumentos de produção de verdade, teremos também que perguntar se esta filiação compromete o potencial crítico da bioética, ou melhor, sua eficácia crítica.

Eficácia talvez seja a idéia com que mais rapidamente se possa concordar. Eficaz na forma como a crença sobre sua utilidade (da bioética) se faz sobre os dados verídicos e verificáveis de seus próprios diagnósticos. Não se questiona a legitimidade por uma relação que isto tem com a causa própria, uma vez que, em mais uma demonstração da eficácia de suas técnicas e verdades, a bioética se pretende acima e autônoma em relação aos indivíduos que a proferem como discurso organizado. Ou seja, tão mais eficaz quanto menos visível se mostra seu comprometimento ou sua fraqueza.

Pela crítica, por outro lado, a bioética teria que enfrentar e expor suas próprias fraquezas; mais que isso, procurar por elas, sondá-las, desconfiar de seu discurso mais legítimo, onde as causas mais apaixonantes estão abrigadas. Mas como ser de tal modo crítico sem perder a eficácia, a credibilidade? Conflito dentro de si mesma, mas não conflito estranho à experiência de nosso tempo.

Do ponto de vista da crítica fundada pelo sujeito moderno, encontraríamos alguns pontos de encontro com este destino forjado para e pela bioética. Para citar um destes, basta tomar o modo como a busca por uma administração responsável da vida se funda numa visão/ antevisão do uso da racionalidade científica e do que este uso implica em termos de excesso, abuso, dominação. Há não só uma idéia de administração da vida como projeto moderno, mas de administração da ciência que administra a vida, onde a vida é a vida plena de sentidos humanos (também modernos) de autonomia, saúde, dignidade, justiça. Há também uma idéia de responsabilidade, quase como uma condição para o destino humano de liberdade ou sua maioridade. Trata-se do apelo à coragem kantiana da tarefa do esclarecimento: "sabes muito bem até onde és capaz de saber? Raciocina enquanto quiseres, mas sabes bem até onde podes raciocinar sem perigo? a crítica dirá, substancialmente, que a nossa liberdade é posta em jogo menos por aquilo que enfrentamos, com mais ou menos coragem, do que pela idéia que fazemos do nosso conhecimento e dos seus limites". ${ }^{23: 4}$

Nada mais moderno e, ao mesmo tempo, tão significativo para situar o destino da bioética - destinada a ser uma crítica da ciência e da técnica - do que lhe estabelecer limites, margens seguras e conscientemente assumidas por seus gestores e executores. Por outro lado, também moderna a pretensão de que esta crítica possa ser suficientemente instrumentalizada e levada a cabo por muitos, ou seja, que tais instrumentos possam estar sob o controle e para o beneficio de todos. Aí a crítica se assentaria numa ilusão de socialização (dos instrumentos da bioética) e do uso coerente, desinteressado (ou bem intencionado) destes espaços e instrumentos. Isto seria desconhecer o caráter ambíguo e litigioso dos desafios e decisões deman-

** Excertos obtidos no site organizado por Goldim² ${ }^{24}$ se referindo a Reich (1979), Roy (1979) e Roy (1995), respectivamente. 
dadas, que é o argumento mesmo da exigência da bioética. Outro conflito em seu próprio seio. Então, ao se assumir uma perspectiva crítica a respeito dos próprios limites da bioética, novamente se voltaria a questão de como controlar seu percurso e seu poder? Como evitar que algo destinado a ser um controle sobre um poder desmedido, também perca suas medidas, abuse, se corrompa? De novo angústia e incerteza. Daí o recurso a confiança que só uma moralidade poderá dar - propor uma bioética como uma nova moralidade, um novo tipo de ética, como se, por assim ser, se atenuasse o conflito, simplesmente, por ser uma ética.

Isto tudo significaria a completa anulação do potencial crítico da bioética? Um destino rumo à um lugar inexistente? $\mathrm{Ou}$, talvez, possa indicar a abertura para outra atitude, que potencialize estas novas sensibilidades que tornam a bioética tão necessária, voltando para si o olhar sensível, politizando os conflitos morais e reconhecendo as diferentes faces da bioética para, em contraste a uma bioética para privilegiados, buscar alternativas, como a Bioética na Perspectiva da Teologia da Libertação, a Bioética Dura ou Bioética Forte, a Bioética Crítica, a Bioética Feminista e Anti-racista, ou a Bioética da Reflexão Autônoma. ${ }^{26}$

A bioética resgatada e abrigada ao seio de múltiplos movimentos políticos, de maior ou menor força contestatória, tem não apenas novas frentes temáticas abertas, mas novos exercícios de autocrítica, pelo menos de crítica dirigida para sua face mais hegemônica (principialista, tradicional, norte americana), revelando-se em suas ambigüidades. Se isto não pode ser considerado aquele destino crítico por excelência, representa, sem dúvida, uma porta lateral, um enfrentamento possível a uma dominação que se estabelece dentro de um discurso. Por mais que não possamos estabelecer seu alcance, os movimentos intelectuais de reação, mesmo sofrendo seus próprios limites de crítica e autocrítica, sem dúvida abrem brechas e estradas secundárias na larga via da bioética internacional.

\section{AINDA QUESTÕES EM ABERTO}

Iniciar um ensaio por um inventário pode significar que algumas escolhas e supostos iniciais marcam seu desenrolar. Mesmo sem o objetivo de construir uma narrativa histórica que fosse capaz de por em evidência estes processos, não se pode prescindir de inventariar, no sentido de arrolar ou declarar alguns desses apoios, jogos e conexões que parecem fazer com que aquele problema aconteça, ou que estejamos sensíveis a ele.
Uma ultima palavra poderia ser para reafirmar que, para além de uma história de fundadores e fatos marcantes, o movimento da bioética não pode ser entendido fora de um movimento mais amplo, no qual diferentes atores (instituições, países, organizações, comunidades científicas, militantes de variadas posições) reivindicam e esforçam-se por harmonizar coisas (valores, metas, mudanças) que pareciam inconciliáveis entre si e com os atuais modelos de desenvolvimento social; coisas como formas de individualidade e comunidade, de solidariedade, justiça e igualdade. Mais do que a busca por argumentos racionais; mais do que a busca pela moralidade das ações justificadas pelos argumentos racionais, este movimento aprende que o argumento racional é negociável e, portanto, moralidades são negociáveis e que nesta negociação há múltiplos sujeitos com direito à palavra, embora em vozes mais ou menos audíveis.

Ressaltar o caráter político deste movimento implica em também reconhecer seu caráter cultural, especialmente pela intimidade entre nossa cultura e nossa ciência. Se estamos assistindo a uma cientifização social de todo conhecimento e se esta é uma oportunidade para reintegrar o conhecimento do que é verdadeiro e do que é bom, ou seja, de nossas formas de conhecimento científico e filosófico, ${ }^{27}$ a bioética seria apenas uma das expressões mais concretas deste processo?

$\mathrm{O}$ atual reconhecimento de que o ocidente não detém o monopólio das boas idéias científicas existentes no mundo, que o divórcio entre razão e valores não se mostrou um principio humano produtivo, desmistifica o conhecimento científico, pela demonstração de sua índole socialmente construída. A isto deve se conjugar a uma reforma metodológica, em que as necessidades das comunidades afetadas pelos produtos da ciência sejam decisivas. ${ }^{28}$ Estas são as questões e o contexto cultural da bioética. Questões que estão presentes nos discursos de filósofos e pesquisadores sociais; que não representam uma grande novidade, mas que atingem as práticas de diferentes áreas técnicas e científicas. Como se a cada um, em seu local, se endereçasse esta questão sobre o valor e a justificativa moral de sua ação. Esta é a questão de Harding.

"De que tipo de conhecimento sobre o mundo empírico, precisamos para podermos simplesmente, viver, e para vivermos mais razoavelmente uns com os outros neste planeta, a partir deste momento? Quem deve constituir o nós que responde a esta pergunta?". ${ }^{28: 92}$ 
Se, frente a primeira parte da questão acima, a bioética tão prontamente se colocou a buscar respostas - e não respostas genéricas, mas praticáveis e resolutivas para aqueles que tem a tarefa de gerir conflitos bastante específicos - frente à segunda parte da questão, há um silêncio constrangedor. Constrangedor, especialmente, porque as respostas aventadas pouco condizem com as regras postas em ação.

\section{REFERENCIAS}

1. Wikler D. Bioethics and social responsability. Bioeth. 1997; 11(3/4):185-6.

2. Marques MB. Em busca de um fórum para bioética na política pública do Brasil. Cad Saúde Pública.1996 Out-Dez; 2(4):443-54.

3. Garrafa V, Diniz D, Guilhem D. Bioetical language and its dialects anda idiolects. Cad. Saúde Publica. 1999; 15(Sup 1):35-42.

4. Pellegrino E. Origem e evolução da bioética. In: Pessini L, Barchifontaine CP, organizadores. Problemas atuais de bioética. $7^{\mathrm{a}}$ ed. São Paulo (SP): Loyola; 1995.

5. Durand G. Introdução geral à bioética. São Paulo (SP): São Camilo/Loyola; 2003.

6. Stepke, FL. Institucionalización de la bioética. Rev Selecciones Bioet. 2002 Ago (2):11-20.

7. Pessini L, Barchifontaine CP. Problemas atuais de bioética. $7^{\mathrm{a}}$ ed. São Paulo: Loyola; 1995.

8. Callahan D. Bioética. Rev Selecciones Bioet. 2002 Ago; (2):29-43.

9. Diniz D, Guilhem D. O que é bioética. São Paulo (SP): Brasiliense; 2005.

10. Jonsen AR. The birth of bioethics. Hastings Cent Rep. 1993 Nov-Dec; 23(6):S1-4.

11. Berlinguer G. Ética da saúde. São Paulo (SP): Hucitec; 1996.

12. Berlinguer G. Bioética Cotidiana. Brasília (DF): Ed. UNB; 2004.

13. Garrafa V. Bioética, poder e injustiça: por uma ética de intervenção. O mundo da Saúde. 2002 Jan-Mar; 26(1):6-15.

14. Stepke FL. Macrobioética y ek proceso de contrucción de la salud. In: Málaga H, organizador. Salud Publica
- enfoque Bioético. Caracas (CO): DISINLIMED; 2005. p.139-44.

15. Foucault M. O cuidado com a verdade. In: Foucault M. Ética, sexualidade, política - Coleção Ditos e escritos V. Rio de Janeiro (RJ): Forense Universitária; 2004. p.240-51.

16. Spink MJP. Trópicos dos discursos sobre risco: riscoaventura como metáfora na modernidade tardia. Cad Saúde Pública. 2001 Nov-Dez; 17(6):1277-311.

17. Potter VR. Bioethics. Bridge to the future. Englewood Cliffs (US): Prentice Hall; 1971.

18. Kottow M. Bioterrorismo, biodefensa, bioética. Cad Saúde Pública. 2003 Jan-Fev; 19(1):297-303.

19. Foucault M. A vontade de saber In: Foucault M. Resumo dos Cursos do Collège de France. Rio de Janeiro (RJ): Zahar; 1997.

20. Foucault M. O nascimento da clínica. $5^{\mathrm{a}}$ ed. Rio de Janeiro (RJ): Forense Universitária; 2001.

21. Dugay P, Hall S, Mackay H, Janes L, Negus K, organizadores. Doing cultural studies: the story of the sony walkman. London (UK): Sage/Open Univesity; 1997.

22. Padilha MIC de S, Ramos FRS, Borenstein MS, Rios CMA. Responsabilidade do pesquisador ou sobre o que dizemos acerca da ética em pesquisa. Texto Contexto Enferm. 2005 Jan-Mar;14(1): 96-105.

23. Foucault M. Iluminismo e crítica: a cura de Paolo Napoli. Roma (IT): Donzelli Edit; 1997. p.31-78.

24. Goldim JR. Núcleo Interinstitucional de Bioética. Conceitos fundamentais em Bioética [página da internet]. Hospital das Clínicas de Porto Alegre. Universidade Federal do Rio Grande do Sul; [acesso 2008 Jul 30]. Disponível em: http:/ / www.bioetica. ufrgs.br/bioet78.htm; http:/ / www.bioetica.ufrgs. br/bioet79.htm

25. Foucault M. Microfísica do Poder. Rio de Janeiro (RJ): Graal; 2000.

26. Garrafa V. Radiografia bioética de um país - Brasil. Acta Bioeth. 2000; 6(1):171-5.

27. Wallerstein I. As estruturas do conhecimento ou quantas formas temos nós de conhecer? In: Santos BS, organizador. Conhecimento prudente para uma vida decente. São Paulo (SP): Cortez; 2004.

28. Santos BS. Conhecimento prudente para uma vida decente - Um discurso sobre as ciências revisitado. São Paulo (SP): Cortez; 2004. 